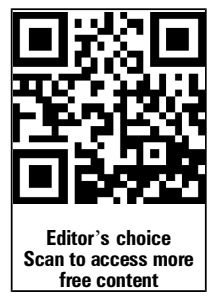

Correspondence to

Dr James Turvill, Department of Gastroenterology, York Hospital, York Teaching Hospitals NHS Foundation Trust, Wigginton Road, York Y031 8HE, UK; james.turvill@york.nhs.uk

Received 11 February 2014 Revised 27 March 2014 Accepted 1 April 2014 Published Online First 16 April 2014
CrossMark

\author{
To cite: Turvill J. Frontline \\ Gastroenterology \\ 2014;5:167-175.
}

\title{
Mapping of Crohn's disease outcomes to faecal calprotectin levels in patients maintained on biologic therapy
}

\begin{abstract}
Background Faecal calprotectin $(\mathrm{FC})$ is a sensitive marker of intestinal mucosal inflammation. The gold standard in Crohn's disease management is mucosal healing. The role of FC to support clinical practice in Crohn's disease is not yet defined.
\end{abstract}

Aims To determine, in patients with Crohn's disease established on biologic therapy: (1) the correlation between disease activity and FC levels, (2) whether FC can predict for relapse and (3) the sensitivity and specificity of the C-reactive protein (CRP) when compared with FC.

Methods In this retrospective, single-site study, Crohn's disease activity, clinical outcomes, FC and CRP of 76 patients established on biologic therapy were reviewed and mapped over time.

Results Patients were mapped for a median of 34 months (IQR 21-57.5). FC levels were determined every 7 (4-13) months on average. Mean FC in quiescent disease was $105 \mu \mathrm{g} / \mathrm{g}$ (SEM 19); in mild disease, 282 (SEM 71); in moderate disease, 611 (SEM 80) and in severe disease, 1314 (SEM 224) ( $p<0.001)$. In asymptomatic patients who relapsed at 6 months, the optimal FC, with an area under the curve of 0.886 ( $p<0.001)$, was 357.5. In discriminating quiescent from active disease $(F C>100 \mu \mathrm{g} / \mathrm{g}$ ) the sensitivity and specificity of CRP were $0.48(0.36$ 0.61 ) and $0.73(0.6-0.85)$, and in mild from moderate or active disease ( $F C>250 \mu \mathrm{g} / \mathrm{g}), 0.60$ (0.43-0.74) and (0.72 (0.60-0.82).

Conclusions FC is an accurate marker of Crohn's disease activity and predicts for relapse, thus providing the clinician time to optimise therapy. FC is a more sensitive marker of Crohn's disease activity than CRP.

\section{INTRODUCTION}

Mucosal healing has become the gold standard in the treatment of Crohn's disease. $^{1}{ }^{2}$ Symptoms cannot be relied upon to reflect mucosal healing, so monitoring of therapeutic effectiveness requires for repeated expensive and invasive radiological and endoscopic tests to be undertaken. ${ }^{3}$ A number of biomarkers have been proposed to help the clinician monitor Crohn's disease activity. ${ }^{4}$ Currently, the C-reactive protein (CRP), an acute-phase reactant, is the most widely used. ${ }^{5-7}$ However, it has not proved sufficiently sensitive to be relied upon. ${ }^{8}$

Calprotectin, a heat-resistant product of neutrophil degranulation that can be detected in the faeces, may be a more promising biomarker. ${ }^{49}$ Faecal calprotectin levels are thought to correlate with mucosal activity in Crohn's disease. ${ }^{10-14}$ If the correlation were close, and a target faecal calprotectin predicting for mucosal healing was identified, then that may become a management goal for therapy in itself. This would reduce the need for more complex confirmatory investigations to be performed. ${ }^{15}$

The challenges of aiming for mucosal healing in Crohn's disease are exemplified in the use of the chimeric antibodies to tumour necrosis factor $\alpha$ (TNF $\alpha)$, infliximab and adalimumab. These 'biologics' are an effective treatment for Crohn's disease, capable alone or in combination with immunosuppressants, of halting an otherwise progressive and costly disease. ${ }^{16-21}$ However, they are expensive, carry significant risk profiles, and the demands of monitoring for indication and efficacy require repeated invasive or expensive radiological or endoscopic tests. 
Since 2004, the department of gastroenterology at York Hospital has used faecal calprotectin to map activity in patients with Crohn's disease along with conventional assessment modalities. This has permitted a longitudinal review of disease activity, clinical outcomes, CRP and faecal calprotectin levels in patients with Crohn's disease maintained on infliximab or adalimumab to be undertaken.

The aims of this study are to

- Identify the correlation between Crohn's disease activity and faecal calprotectin levels.

- Determine whether faecal calprotectin levels can be used to predict for clinical relapse in asymptomatic patients.

- Compare the sensitivity and specificity of faecal calprotectin and CRP.

\section{METHODS}

This has been a retrospective review of patients attending York Hospital for the management of Crohn's disease, from the period 2004 to 2013. All patients who were established on maintenance infliximab or adalimumab were eligible. Patients were identified from pharmacy records cross-checked with the hospital Core Patient Database (CPD). The CPD was also used to record demographic data, the Montreal classification of Crohn's disease, disease activity and patient symptomatology, faecal calprotectin and CRP in order to enter the patient into the study. ${ }^{22}$ Previous surgery, concomitant medical therapy and the use of antiplatelet therapy, anticoagulants and non-steroidal anti-inflammatory drugs (NSAID) were recorded.

From this point of entry, the subsequent course of each patient was mapped in terms of disease activity and clinical outcomes. On reaching either of these end points, an episode was closed and the patient was restaged once more by recording Crohn's disease activity and clinical outcomes, alongside faecal calprotectin and CRP levels. This cycle was repeated until the anti-TNF $\alpha$ therapy ceased, or 2013, permitting sequential correlation of faecal calprotectin levels to the clinical course of the patient.

It is important to note that the use of faecal calprotectin during this time was not subject to a protocol and so, on a number of occasions, it was used to support clinical decision making in the absence of a formal assessment of Crohn's disease. For the purposes of this study, a patient episode could only be recorded when disease activity or a defined clinical outcome was determined along with a contemporaneous faecal calprotectin and CRP.

For the purpose of the study, Crohn's disease activity was recorded on the basis of endoscopic, radiologic and histology findings as reported at the time by the responsible clinician. Clinical descriptions of disease activity were used, notably quiescent, mild, moderate or severe activity.

Clinical outcomes were recorded as surgery for Crohn's disease, admissions to hospital for Crohn's disease, symptomatic relapse or the need for escalation of medical therapy as judged by the responsible clinician. The Crohn's Disease Activity Index was not routinely recorded in clinical practice. Instead, symptomatic remission was recorded when the responsible clinician at the time judged that there were no symptoms attributable to active Crohn's disease. ${ }^{23}$ Relapse was recorded when new symptoms arose attributable to active Crohn's disease. Symptoms used to make this judgement were diarrhoea, abdominal pain and malaise.

A polyclonal ELISA (PhiCal test) was used to determine the faecal calprotectin level. The normal cut-off is taken to be $50 \mu \mathrm{g} / \mathrm{g}$, in line with the manufacturer's guidance. Initially, samples were sent on to the department of clinical biochemistry, King's College Hospital, London, for testing. From 2006, the same assay was brought inhouse. A quality control sample set at a level of 150 was present in every test batch, and with this, the coefficient of variation was 5\%.

CRP assay was run on a Beckman Coulter AU2700 analyser using Beckman Coulter reagents; the principle of the test being immunoturbidimetry. Absorbance of aggregates derived from a buffered serum or plasma sample and antihuman CRP antibodies at $340 \mathrm{~nm}$ is taken to be proportional to the CRP concentration in the sample. A normal result is $<5 \mathrm{mg} / \mathrm{L}$.

Data are presented as median with IQR or mean and SEM. Descriptive statistics to calculate sensitivity, specificity, negative and positive predictive value (NPV and PPV) were used, and where appropriate, $t$ test and analysis of variance (ANOVA) were applied. The likelihood ratio for faecal calprotectin to predict for relapse was calculated using receiver-operator characteristics curve analysis.

This retrospective research study (YOR-A02211) was sponsored by, and NHS management permission obtained from, York Teaching Hospital NHS Trust.

\section{RESULTS}

\section{Demographics}

From 2004, 76 patients were identified who were established and maintained on infliximab or adalimumab, and in whom a profile of disease activity or clinical outcome and faecal calprotectin monitoring was generated (figure 1). The median duration of follow-up for the 76 patients was 34 months (IQR 21-57.5), and median frequency of review 7 months (IQR 4-13). From this, 195 periods of review were identified that could be mapped against faecal calprotectin levels.

The Montreal classification of disease, additional immunosuppressant and steroid therapy, and previous surgery for Crohn's disease for all patients are presented in table 1 . Use of antiplatelet therapy, anticoagulants and NSAIDs is recorded here as relevant concomitant medication. 


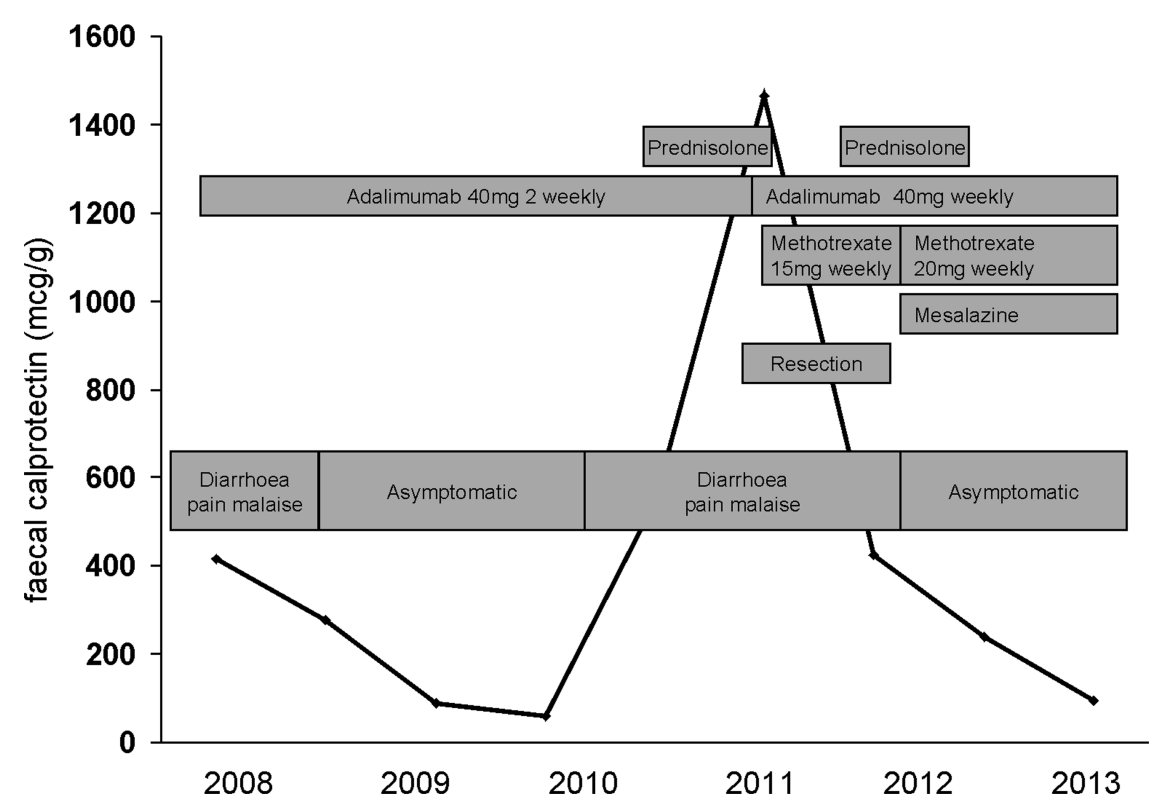

Figure 1 Schematic of mapping symptomatology, medical therapy, surgery and faecal calprotectin in an individual patient over time.

Table 1 Crohn's disease phenotype, previous surgery and medical therapy

\begin{tabular}{|c|c|c|}
\hline Crohn's disease & Number & $\%$ \\
\hline \multicolumn{3}{|l|}{ Age at diagnosis } \\
\hline A1 & 15 & 20 \\
\hline $\mathrm{A} 2$ & 49 & 64 \\
\hline A3 & 12 & 16 \\
\hline \multicolumn{3}{|l|}{ Location } \\
\hline L1 & 27 & 36 \\
\hline L2 & 20 & 26 \\
\hline L3 & 28 & 37 \\
\hline L4 & 1 & 1 \\
\hline \multicolumn{3}{|l|}{ Behaviour } \\
\hline B1 & 37 & 49 \\
\hline B2 & 32 & 42 \\
\hline B3 & 7 & 9 \\
\hline \multicolumn{3}{|l|}{ Perianal disease } \\
\hline Present & 17 & 29 \\
\hline \multicolumn{3}{|l|}{ Biologic therapy } \\
\hline Infliximab & 61 & 80 \\
\hline Adalimumab & 15 & 20 \\
\hline Both & 3 & 4 \\
\hline \multicolumn{3}{|l|}{ DMARD therapy } \\
\hline Azathioprine & 29 & 38 \\
\hline 6-Mercaptopurine & 7 & 9 \\
\hline Methotrexate & 7 & 9 \\
\hline Steroid therapy & 18 & 24 \\
\hline \multicolumn{3}{|l|}{ Prior surgery } \\
\hline Resection & 36 & 47 \\
\hline Stricturoplasty & 1 & 1 \\
\hline Perianal & 8 & 11 \\
\hline \multicolumn{3}{|c|}{ Relevant concomitant medication } \\
\hline NSAID & 1 & 1 \\
\hline
\end{tabular}

During the period of review, disease activity classification was revised in $45 \%$ of patients.

1. Correlation between Crohn's disease activity and faecal calprotectin levels.

Disease activity was determined endoscopically in $51 \%$ of cases and radiologically in 53\% of cases (MR: 39\%; CT: 14\%). A significant difference in faecal calprotectin levels was demonstrated when comparing patients with quiescent, mild, moderate or severe disease $(p<0.01)$. This correlation is presented logarithmically (figure 2 ).

In table 2 the mean faecal calprotectin (SEM) is presented according to Crohn's disease activity. A faecal calprotectin of $<250 \mathrm{mcg} / \mathrm{g}$ had a sensitivity of 0.92 $(0.82-0.98)$ and a specificity of $0.79(0.67-0.85)$ for distinguishing quiescent or mild disease from moderate or severe disease, giving a NPV of $0.90(0.78-$ $0.98)$.

None of the patients with quiescent or mildly active Crohn's disease were symptomatic compared with half of those with moderately active and all of those with severe disease activity.

Subsequent clinical outcomes of patients in each disease activity group during the recorded period of review are also presented in table 2. From this, one can see that the chance of requiring an escalation of therapy over the subsequent 16 months was $5 \%$ if the patient had a faecal calprotectin of $100 \mathrm{mcg} / \mathrm{g}$. Fewer than $10 \%$ of those patients with quiescent or mild disease required escalation of therapy during the mean period of 14 months follow-up compared with over $70 \%$ in those with moderate or severe disease.

Subgroup analysis of disease activity and faecal calprotectin based on the Montreal classification and previous surgery was also performed (tables 3 and 4). There was no consistent difference in disease 


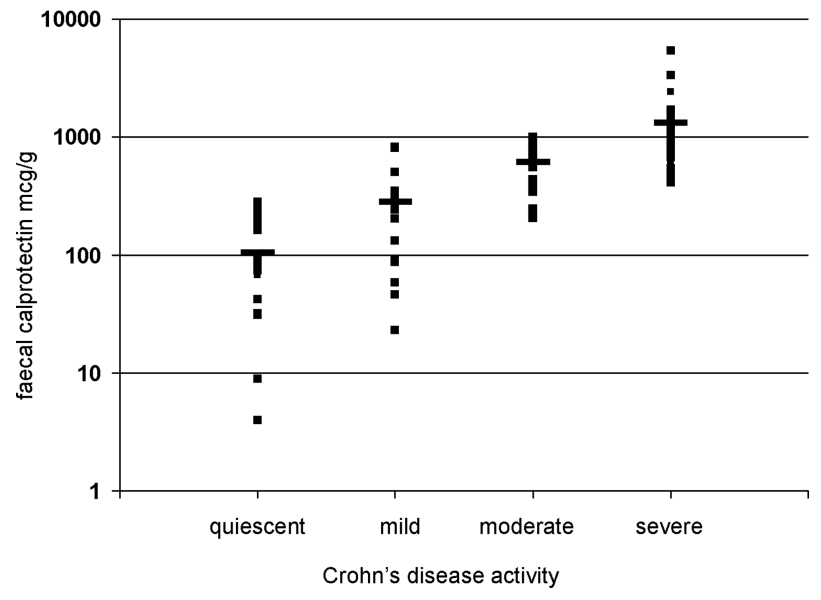

Figure 2 Faecal calprotectin levels plotted against Crohn's disease activity.

phenotype or the effects of surgery on the correlation between disease activity and faecal calprotectin levels.

Twenty-nine patients were additionally taking azathioprine, seven were taking 6-mercaptopurine and seven methotrexate. No differences in faecal calprotectin levels and disease activity were identified between those taking immunomodulator therapies and those not (table 5).

\section{Induction of symptomatic remission}

The mean faecal calprotectin level prior to induction with infliximab or adalimumab was $1349 \mathrm{mcg} / \mathrm{g}$ (SEM 175). There was no correlation between the level at induction and subsequent clinical outcome or disease activity. However, a reduction of faecal calprotectin to $30 \%$ or less of the preinduction value was found to have a PPV of $0.89(0.73-0.96)$ for symptomatic remission, and a NPV of 0.7 (0.48-0.88).

2. Faecal calprotectin predicts for clinical relapse in asymptomatic patients.

One hundred and fourteen episodes of clinical remission with faecal calprotectin monitoring were recorded.

The faecal calprotectin of those patients who remained in symptomatic remission over the subsequent 3, 6 and 12 months was compared with those who went on to relapse during that time (table 6). Patients with a faecal calprotectin of $<250 \mathrm{mcg} / \mathrm{g}$ had
Table 3 Crohn's disease activity and faecal calprotectin based upon the Montreal disease classification

\begin{tabular}{|c|c|c|c|c|}
\hline \multirow{3}{*}{$\begin{array}{l}\text { Montreal } \\
\text { classification }\end{array}$} & \multicolumn{4}{|c|}{ Mean faecal calprotectin (SEM) } \\
\hline & \multicolumn{4}{|c|}{ Crohn's disease activity } \\
\hline & Quiescent & Mild & Moderate & Severe \\
\hline \multicolumn{5}{|l|}{ Age } \\
\hline A1 & $32(28)$ & $246(190)$ & $847(105)$ & $1608(529)$ \\
\hline $\mathrm{A} 2$ & $92(27)$ & $292(85)$ & $615(89)$ & $1369(310)$ \\
\hline A3 & $177(38)$ & 499 & 345 & - \\
\hline $\mathrm{p}$ Value & ns & ns & ns & ns \\
\hline \multicolumn{5}{|l|}{ Behaviour } \\
\hline B1 & $108(33)$ & $195(62)$ & 789 (134) & $2223(865)$ \\
\hline B2 & $99(32)$ & 379 (109) & $658(103)$ & $1038(183)$ \\
\hline B3 & 92 & 92 & 204 & 1381 \\
\hline$p$ Value & ns & ns & ns & ns \\
\hline \multicolumn{5}{|l|}{ Location } \\
\hline L1 & $100(44)$ & $373(177)$ & $302(47)$ & $1031(264)$ \\
\hline L2 & $101(25)$ & $140(50)$ & 861 & $2344(1031)$ \\
\hline L3 & $113(36)$ & $316(113)$ & $773(82)$ & $1188(264)$ \\
\hline$p$ Value & ns & ns & $<0.01$ & ns \\
\hline \multicolumn{5}{|l|}{ Perianal disease } \\
\hline Yes & $86(31)$ & 92 & 471 (135) & $1484(103)$ \\
\hline No & $119(27)$ & $296(75)$ & $667(97)$ & $1148(245)$ \\
\hline $\mathrm{p}$ Value & ns & ns & ns & ns \\
\hline
\end{tabular}

a PPV of $0.94(0.83-0.98)$ for remaining in remission during the subsequent 12 months (NPV of 0.63 (0.39-0.83)).

This permitted a prediction of clinical relapse at 3 and 12 months based on an initial faecal calprotectin (table 7).

The area under the curve was $0.886(\mathrm{p}<0.001)$ for clinical relapse at 6 months with the optimal faecal calprotectin cut-off level being $357.5 \mu \mathrm{g} / \mathrm{g}$ (figure 3).

3. Comparison of faecal calprotectin and CRP.

One hundred and ten episodes of disease activity or clinical outcome, faecal calprotectin and CRP were reviewed. CRP proved to be an insensitive marker of disease activity or clinical outcome in this group of patients. Further it was much less able to distinguish disease severity. Thus, on $79 \%$ of occasions when the faecal calprotectin was elevated, the CRP was normal

Table 2 Crohn's disease activity, faecal calprotectin levels and subsequent clinical outcomes

\begin{tabular}{|c|c|c|c|c|c|c|}
\hline \multirow{2}{*}{$\begin{array}{l}\text { Crohn's disease } \\
\text { activity }\end{array}$} & \multirow{2}{*}{$\begin{array}{l}\text { Mean faecal calprotectin } \\
\text { (mcg/g) } \\
\text { (SEM) }\end{array}$} & \multirow[b]{2}{*}{ Number } & \multirow{2}{*}{$\begin{array}{l}\text { Symptomatic at } \\
\text { assessment (\%) }\end{array}$} & \multirow{2}{*}{$\begin{array}{l}\text { Mean duration of review } \\
\text { (months) } \\
\text { (SEM) }\end{array}$} & \multicolumn{2}{|c|}{$\begin{array}{l}\text { Subsequent } \\
\text { escalation of } \\
\text { treatment (\%) }\end{array}$} \\
\hline & & & & & Medical & Surgical \\
\hline Quiescent & $105(19)$ & 19 & 0 & $16.5(2.4)$ & 0 & 5 \\
\hline Mild & $282(71)$ & 14 & 0 & $11.7(2.5)$ & 14 & 7 \\
\hline Moderate & $611(80)$ & 14 & 54 & $7.5(1.6)$ & 43 & 14 \\
\hline Severe & $1314(224)$ & 24 & 100 & $9.5(1.5)$ & 54 & 25 \\
\hline
\end{tabular}


Table 4 Crohn's disease activity and faecal calprotectin levels with or without prior surgery

\begin{tabular}{llll}
\hline & \multicolumn{2}{l}{$\begin{array}{l}\text { Mean faecal calprotectin } \\
\text { (SEM) }\end{array}$} & \\
\cline { 2 - 3 } & \multicolumn{2}{l}{$\begin{array}{l}\text { Previous resection/ } \\
\text { stricturoplasty }\end{array}$} & \\
\cline { 2 - 3 } Disease activity & No & Yes & p Value \\
\hline Quiescent & $120(25)$ & $89(34)$ & ns \\
Mild & $365(124)$ & $199(63)$ & ns \\
Moderate & $569(124)$ & $612(120)$ & ns \\
Severe & $1463(336)$ & $987(196)$ & ns \\
\hline
\end{tabular}

$(<5 \mathrm{mg} / \mathrm{L})$. By contrast, the mean elevated CRP value was only 12 while the simultaneous mean elevated faecal calprotectin was 888 . In figure 4 , the percentage of patients with a raised CRP is plotted against their faecal calprotectin.

In discriminating quiescent from active disease (the faecal calprotectin cut-off at $>100 \mathrm{mcg} / \mathrm{g}$ ) the sensitivity of CRP was $0.48(0.36-0.61)$ and the specificity was $0.73(0.6-0.85)$. And in identifying mild from moderate or severe Crohn's disease (a faecal calprotectin set at $>250 \mathrm{mcg} / \mathrm{g}$ ), the sensitivity for CRP was $0.60(0.43-0.74)$ and the specificity $(0.72 \quad(0.60-$ $0.82)$.

When assessed independent of faecal calprotectin a CRP $>5$ had a sensitivity of $0.6(0.27-0.86)$ and a specificity of $0.67(0.35-0.89)$ for clinical disease activity.

As a marker of risk of clinical relapse in the next 12 months, CRP had a PPV of $0.31(0.14-0.57)$ and a NPV of 0.77 (0.56-0.90).

\section{DISCUSSION}

This retrospective study maps Crohn's disease activity, clinical outcomes and faecal calprotectin in patients followed-up at York Hospital between 2004 and 2013. It has reviewed over 250 patient-years of Crohn's disease and, different from other studies where a point faecal calprotectin has been performed, this study provides a continuum of clinically significant events punctuated by repeated faecal calprotectin measurements. It has identified the role of faecal calprotectin as an accurate and relevant biomarker of disease activity and as a timely predictor of relapse,

Table 5 Crohn's disease activity and faecal calprotectin levels with or without additional immunomodulator therapy

\begin{tabular}{llll}
\hline & \multicolumn{2}{l}{ Mean faecal calprotectin (SEM) } & \\
\cline { 2 - 3 } Disease & No & Immunomodulator & \\
activity & immunomodulation & therapy & p Value \\
\hline Quiescent & $121(25)$ & $103(34)$ & ns \\
Mild & $170(74)$ & $376(105)$ & ns \\
Moderate & $649(109)$ & $583(220)$ & ns \\
Severe & $1105(164)$ & $1641(582)$ & ns \\
\hline
\end{tabular}

Table 6 Mean faecal calprotectin level in asymptomatic patients who remained in remission or subsequently relapsed

\begin{tabular}{|c|c|c|c|}
\hline \multirow{2}{*}{$\begin{array}{l}\text { Period of } \\
\text { review } \\
\text { (months) }\end{array}$} & \multicolumn{2}{|c|}{$\begin{array}{l}\text { Mean faecal calprotectin at } 0 \text { months } \\
\text { (SEM) }\end{array}$} & \multirow[b]{2}{*}{ p Value } \\
\hline & $\begin{array}{l}\text { Asymptomatic at } \\
\text { review }\end{array}$ & $\begin{array}{l}\text { Relapse at } \\
\text { review }\end{array}$ & \\
\hline 3 & $185(21.5)$ & $553(219)$ & $<0.01$ \\
\hline 6 & $141(19)$ & $633(106)$ & $<0.01$ \\
\hline 12 & $104(14)$ & $626(99)$ & $<0.01$ \\
\hline
\end{tabular}

thus providing the clinician time to optimise therapy. The study lacks the benefits of prospective research and a formal definition of Crohn's disease activity. There was no formal scheduling of faecal calprotectin monitoring, and so, the study maps disease activity and clinical outcomes only when investigations were initiated or recorded by one of the five responsible clinicians in normal clinical practice. However, the purpose of this study has not been to define the natural history of faecal calprotectin levels in Crohn's disease per se, but to define its clinical usefulness.

A pragmatic approach to recording disease activity has been used based on independent clinician reporting of endoscopic, histologic and radiologic findings. Similarly, while a tool, such as the Crohn's Disease Activity Index, could not be used to define clinical remission or relapse in these patients, judgements about these outcomes have been made, based on diarrhoea, pain and malaise, by the responsible clinician at the time of the consultation. Additional clinical outcomes recorded were the need for surgery, hospital admission or escalation of medical therapy. It is judged, therefore, that the findings accurately reflect the usefulness of this non-invasive biomarker in clinical practice. ${ }^{24}$

The study highlights a number of key elements to direct in the clinical use of faecal calprotectin. First, faecal calprotectin correlates with the severity of Crohn's disease activity in a linear (logarithmic) fashion from quiescent through to severe disease. This is not dependent upon the faecal calprotectin level prior to the introduction of anti-TNF $\alpha$ therapy or generally upon the nature of the Crohn's disease or the additional use of immunomodulator therapy. Quiescent Crohn's disease is associated with a faecal calprotectin of approximately $100 \mathrm{mcg} / \mathrm{g}$ or less.

Table 7 Risk of clinical relapse in over the subsequent 3 or 12 months dependent upon baseline faecal calprotectin

\begin{tabular}{lcc}
\hline \multirow{2}{*}{$\begin{array}{l}\text { Faecal calprotectin at } \\
0 \text { months }(\mu \mathrm{g} / \mathrm{g})\end{array}$} & \multicolumn{2}{l}{ Percentage risk of clinical relapse } \\
\cline { 2 - 3 } & $0-3$ months & $3-12$ months \\
\hline$<100$ & 2 & 2 \\
$100-500$ & 5 & 13 \\
$>500$ & 33 & 86 \\
\hline
\end{tabular}




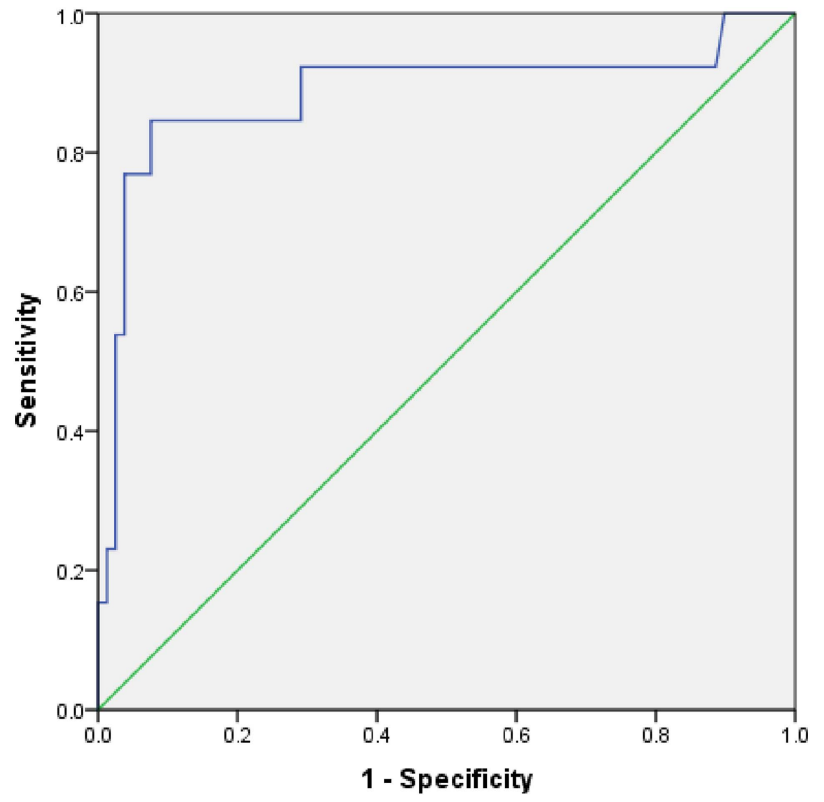

Diagonal segments are produced by ties.

Figure 3 Receiver-operator characteristic curve (ROC) for faecal calprotectin levels predicting for clinical relapse within 6 months in asymptomatic patients with Crohn's disease (area under the curve $0.886 p<0.001$ )

Here, all patients remained well indefinitely with the exception of one who required surgery for a noninflamed fibro-stenotic stricture.

Above a level of $250 \mathrm{mcg} / \mathrm{g}$, there is an increasing risk of clinically significant mucosal disease activity. However, the chances of being clinically symptomatic with a faecal calprotectin of less than $250 \mathrm{mcg} / \mathrm{g}$ are small. Faecal calprotectin is a more sensitive test than it is specific, so caution must be exercised when drawing conclusions from a single elevated test. Indeed it is our practice to repeat the test if it initially points to uncontrolled disease. ${ }^{25}$ This reflects the

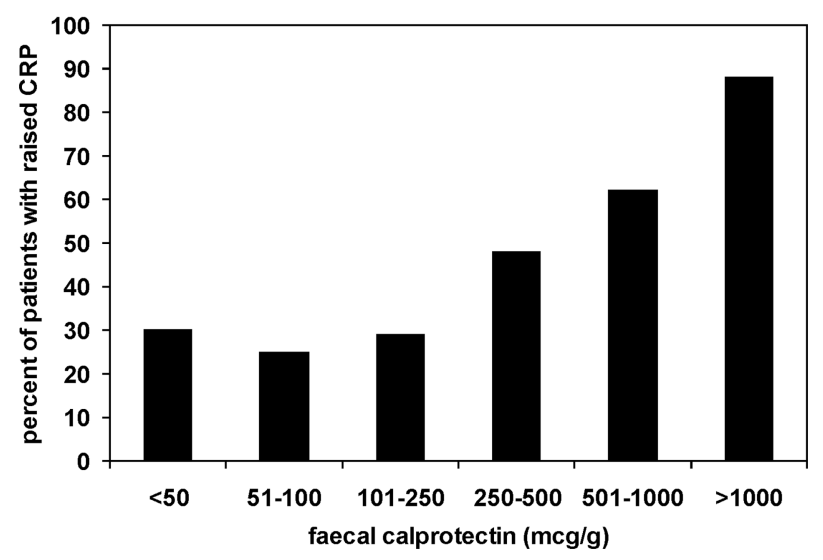

Figure 4 C-reactive protein (CRP) correlates poorly when compared with faecal calprotectin in Crohn's disease. advantage of using faecal calprotectin as a monitoring tool rather than as a point test. ${ }^{26}$

These observations are consistent with previous published studies that have not benefited from longterm patient follow-up. ${ }^{26-32}$

The subgroup analysis based on Montreal classification found little difference in these key indicators of disease activity; however, some of the numbers in the subgroup analysis were small. A significant difference was found in faecal calprotectin levels in patients with moderate ileo-colonic, rather than ileal, disease presumably due to the potential surface area of calprotectin shedding. ${ }^{33}$

Trends were also seen in patients who had undergone an intestinal resection. This may reflect challenges in postoperative radiological reporting of disease activity.

Interestingly, the presence of perianal disease did not alter the validity of faecal calprotectin testing.

Not surprisingly, few patients were taking prescribed NSAIDs, though the study was unable to exclude over-the-counter usage. Also, the relative youth of the patient group explains the absence of antiplatelet therapy and anticoagulants in the study population.

Second, the faecal calprotectin accurately predicts for future clinical outcomes and, by implication, efficacy of therapy, in Crohn's disease. By monitoring the faecal calprotectin level when a patient is asymptomatic, the clinician is provided a window of up to 12 months in which to optimise therapy and so prevent clinical relapse. ${ }^{34}$ In practice, this means that the clinician can be confident that symptoms in a patient with a faecal calprotectin of $<250 \mu \mathrm{g} / \mathrm{g}$ are likely to be functional and can be treated expectantly, while a withdrawal of immunomodulator therapy is reasonable to consider in a patient with a faecal calprotectin of $100 \mu \mathrm{g} / \mathrm{g}$ or less. Further, that failure to respond to a faecal calprotectin of $>500 \mu \mathrm{g} / \mathrm{g}$ will lead to rapid progression of disease.

The strength of the predictive power of faecal calprotectin means that, for the patient, optimisation of therapy may be achieved without the necessity of recourse to repeated invasive investigations. For healthcare providers, this has a significant potential for cost savings. This observation must be underpinned by prospective research.

Currently, it is not reasonable to infer exactly the same predictive role for faecal calprotectin in those patients maintained on immunosuppressant therapy rather than anti-TNF $\alpha$ therapy.

Finally, faecal calprotectin provides an entirely new insight as a biomarker of Crohn's disease when compared to CRP. Clinicians cannot rely on the CRP to give the sort of information on real-time mucosal disease activity that the faecal calprotectin provides. CRP lacks the specificity in patients with a faecal calprotectin of $<250 \mathrm{mcg} / \mathrm{g}$ to reassure the clinician, 


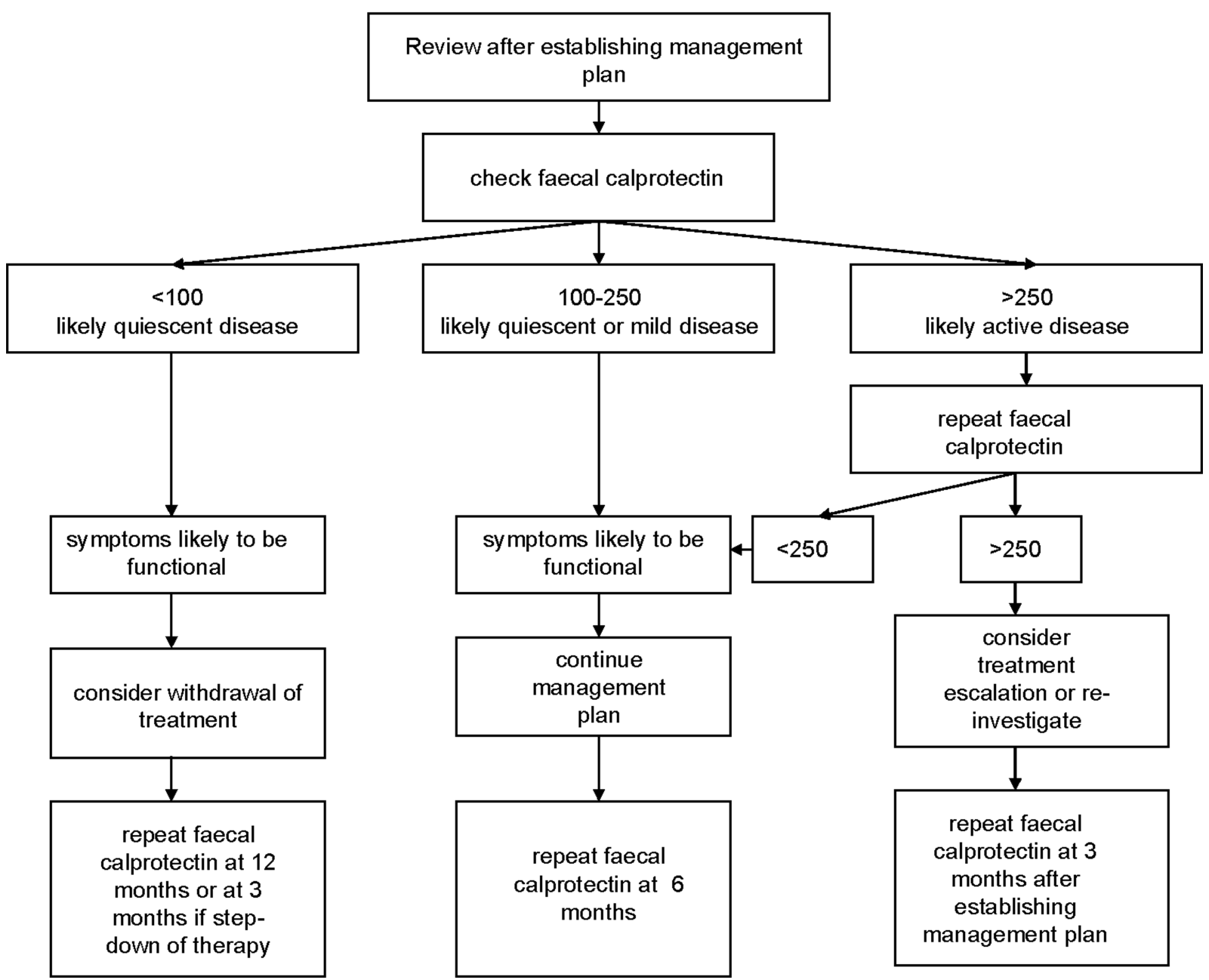

Figure 5 Proposed guidelines for the use of faecal calprotectin in the management of patients with Crohn's disease established on biologic therapy.

neither is it sensitive enough to identify disease activity or risk of imminent relapse in patients with a faecal calprotectin $>250 \mathrm{mcg} / \mathrm{g}$ or $>500 \mathrm{mcg} / \mathrm{g}$, respectively. Faecal calprotectin should be an available test in all centres caring for patients with Crohn's disease.

Based on these observations, an algorithm for using faecal calprotectin monitoring to support the clinician in the management of patients with Crohn's disease is proposed (figure 5). Here, the target of medical therapy is to keep the faecal calprotectin $<100 \mathrm{mcg} / \mathrm{g}$, however, a value of $<250 \mathrm{mcg} / \mathrm{g}$ represents low risk. If this is achieved, intestinal symptoms reported by patients are likely to be functional. Monitoring could continue every 6 months. Patients with a faecal calprotectin $<100 \mathrm{mcg} / \mathrm{g}$ have quiescent disease, and here it may be appropriate to consider step-down of treatment. ${ }^{29} 3536$ A faecal calprotectin $>250 \mathrm{mcg} / \mathrm{g}$ should be repeated; if persistently raised, an escalation of therapy or intervention is indicated. Any change to therapy would prompt a repeat faecal calprotectin in 3 months.

In conclusion, faecal calprotectin is a highly sensitive real-time biomarker of Crohn's disease mucosal activity. It provides an insight into disease ahead of symptoms, so predicting for disease outcomes without recourse to expensive and invasive testing. Should these findings be replicated in a prospective study, faecal calprotectin will become embedded in the algorithm of optimal care to direct clinicians, reduce risk and minimise costs.

\section{What is already known on this topic}

Faecal calprotectin levels correlate with mucosal inflammation in Crohn's disease.

\section{What this study adds}

Faecal calprotectin can be used to monitor Crohns disease activity in patients. 
How might it impact on clinical practice in the foreseeable future

Faecal calprotectin monitoring should be incorporated into Crohn's disease management to facilitate clinical and cost effectiveness.

Correction notice One of the key messages boxes has been updated since published Online First.

Acknowledgements I would like to acknowledge Dr Deborah Phillips, Research Adviser, York Teaching Hospital NHS Foundation Trust; Dr Victoria Allgar, Statistician, Hull York Medical School, York; Dr Ian Holbrook, Top Grade Biochemist, York Teaching Hospital NHS Foundation Trust (Retired) and Ms Sally Slack, Clinical Biochemist, York Teaching Hospital NHS Foundation Trust, for their support in the completion of this study.

\section{Competing interests None.}

Provenance and peer review Not commissioned; externally peer reviewed.

\section{REFERENCES}

1 Neurath MF, Travis SP. Mucosal healing in inflammatory bowel diseases: a systematic review. Gut 2012;61:619-35.

2 Daperno M, Castiglione F, de Ridder L, et al.; Scientific Committee of the European Crohn's and Colitis Organization. Results of the 2nd part Scientific Workshop of the ECCO. II: Measures and markers of prediction to achieve, detect, and monitor intestinal healing in inflammatory bowel disease. J Crohns Colitis 2011;5:484-98.

3 af Björkesten CG, Nieminen U, Turunen U, et al. Surrogate markers and clinical indices, alone or combined, as indicators for endoscopic remission in anti-TNF-treated luminal Crohn's disease. Scand J Gastroenterol 2012;47:528-37.

4 Desai D, Faubion WA, Sandborn WJ. Review article: biological activity markers in inflammatory bowel disease. Aliment Pharmacol Ther 2007;25:247-55.

5 Boiliviant M, Leoni M, Tariciotti $\mathrm{D}$, et al. The clinical significance of serum $\mathrm{C}$ reactive protein in Crohn's disease: result of a prospective longitudinal study. J Clin Gastroenterol 1988;10:401-5.

6 Consigney Y, Modigliani R, Colombel JF, et al. Biologic markers of short-term relapse in Crohn's disease. Gastroenterology 2001;20(Suppl.):A53.

7 Wright JP, Young GO, Tigler-Wybrandi N. Predictors of acute relapse of Crohn's disease. A laboratory and clinical study. Dig Dis Sci 1987;32:164-70.

8 Solem CA, Loftus EV Jr, Tremaine WJ, et al. Correlation of C-reactive protein with clinical, endoscopic, histologic, and radiographic activity in inflammatory bowel disease. Inflamm Bowel Dis 2005;11:707-12.

9 Tibble JA, Bjarnason I. Non-invasive investigations of inflammatory bowel disease. World J Gastroenterol 2001;7: 460-5.

10 Fagerhol MK, Dale I, Anderson I. Release and quantification of leukocyte derived protein (L1). Scand J Haematol 1980;24:393-8.

11 Tibble JA, Teahan K, Thjodleifssan B, et al. A simple method for assessing intestinal inflammation in Crohn's disease. Gut $2000 ; 47: 506-13$.
12 Roseth AG, Aadland E, Jahnsen J, et al. Assessment of disease activity in ulcerative colitis by faecal calprotectin, a novel granulocyte marker protein. Digestion 1997;58: 176-80.

13 Roseth AG, Fagerhol MK, Aadland E, et al. Assessment of neutrophil dominating protein calprotectin in feces. A methodologic study. Scand J Gastroenterol 1992;27: 793-8.

14 Taehon K, Roseth AG, Foster R, et al. Fecal calprotectin: a simple sensitive quantitative measure of intestinal inflammation in man (abstract). Gastroenterology 1997;112(Suppl.):A1103.

15 Mindemark M, Larsson A. Ruling out IBD: estimation of the possible economic effects of pre-endoscopic screening with F-calprotectin. Clin Biochem 2012;45:552-5.

16 Hanauer SB, Sandborn WJ, Rutgeerts P, et al. Human anti-tumor necrosis factor monoclonal antibody (adalimumab) in Crohn's disease: the CLASSIC-I trial. Gastroenterology 2006;130:323-33.

17 Sandborn WJ, Hanauer SB, Rutgeerts P, et al. Adalimumab for maintenance treatment of Crohn's disease: results of the CLASSIC II trial. Gut 2007;56:1232-9.

18 van Dullemen HM, van Deventer SJH, Hommes DW, et al. Treatment of Crohn's disease with anti-tumor necrosis factor chimeric monoclonal antibody (cA2). Gastroenterology 1995;109:129-35.

19 Rutgeerts P, D’Haens G, Targan S, et al. Efficacy and safety of retreatment with anti-tumor necrosis factor antibody (infliximab) to maintain remission in Crohn's disease. Gastroenterology 1999;117:761-9.

20 Hanauer SB, Feagan BG, Lichtenstein GR, et al.; ACCENT I Study Group. Maintenance infliximab for Crohn's disease: the ACCENT I randomised trial. Lancet 2002;359:1541-9.

21 Colombel JF, Sandborn WJ, Rutgeerts P, et al. Adalimumab for maintenance of clinical response and remission in patients with Crohn's disease: the CHARM trial. Gastroenterology 2007;132:52-65.

22 Silverberg MS, Satsangi J, Ahmad T, et al. Toward an integrated clinical, molecular and serological classification of inflammatory bowel disease: Report of a Working Party of the 2005 Montreal World Congress of Gastroenterology. Can J Gastroenterol 2005;19(Suppl A):5-36.

23 Best WR, Becktel JM, Singleton JW, et al. Development of a Crohn's disease activity index. National Cooperative Crohn's Disease Study. Gastroenterology 1976;70:439-44.

24 Sipponen T, Savilahti E, Kolho KL, et al. Crohn's disease activity assessed by fecal calprotectin and lactoferrin: correlation with Crohn's disease activity index and endoscopic findings. Inflamm Bowel Dis 2008;14:40-6.

25 Turvill JL. High negative predictive value of a normal faecal calprotectin in patients with symptomatic intestinal disease. Frontline Gastroenterol 2012;3:121-28.

26 Laharie D, Mesli S, El Hajbi F, et al. Prediction of Crohn's disease relapse with faecal calprotectin in infliximab responders: a prospective study. Aliment Pharmacol Ther 2011;34:462-9.

27 D'Haens G, Ferrante M, Vermeire S, et al. Fecal calprotectin is a surrogate marker for endoscopic lesions in inflammatory bowel disease. Inflamm Bowel Dis 2012;18:2218-24.

28 Molander P, af Björkesten CG, Mustonen H, et al. Fecal calprotectin concentration predicts outcome in inflammatory bowel disease after induction therapy with TNF $\alpha$ blocking agents. Inflamm Bowel Dis 2012;18:2011-17. 
29 Louis E, Mary JY, Vernier-Massouille G, et al.; Groupe D'etudes Thérapeutiques Des Affections Inflammatoires Digestives. Maintenance of remission among patients with Crohn's disease on antimetabolite therapy after infliximab therapy is stopped. Gastroenterology 2012;142: 63-70.

30 Wagner M, Peterson CG, Ridefelt P, et al. Fecal markers of inflammation used as surrogate markers for treatment outcome in relapsing inflammatory bowel disease. World J Gastroenterol 2008;14:5584-9.

31 García-Sánchez V, Iglesias-Flores E, González R, et al. Does fecal calprotectin predict relapse in patients with Crohn's disease and ulcerative colitis? J Crohns Colitis 2010; 4:144-52.

32 Sipponen T, Savilahti E, Kärkkäinen P, et al. Fecal calprotectin, lactoferrin, and endoscopic disease activity in monitoring
anti-TNF-alpha therapy for Crohn's disease. Inflamm Bowel Dis 2008;14:1392-8.

33 Mao R, Xiao YL, Gao X, et al. Fecal calprotectin in predicting relapse of inflammatory bowel diseases: a meta-analysis of prospective studies. Inflamm Bowel Dis 2012;18:1894-9.

34 Molander P, Sipponen T, Kemppainen H, et al. Achievement of deep remission during scheduled maintenance therapy with TNF $\alpha$-blocking agents in IBD. J Crohns Colitis 2013;7:730-5.

35 Infliximab (review) and adalimumab for the treatment of Crohn's disease. NICE technology appraisal guidance 187. 2010. http://www.nice.org.uk/guidance/TA187

36 Pittet V, Froehlich F, Maillard MH, et al.; the EPACT-II Update Panellists. When do we dare to stop biological or immunomodulatory therapy for Crohn's disease? Results of a multidisciplinary European expert panel. J Crohns Colitis 2013;7:820-6. 